\title{
Assessment of Meteorological Drought characteristics using Standardized precipitation Index for Ajmer District, Rajasthan, India
}

\author{
Gaurav Sharma ${ }^{1}$, Chandra Kishor Kumar ${ }^{1 *}$ and Ankit Kumar² \\ ${ }^{1}$ Department of Farm Engineering, Institute of Agricultural Sciences, Banaras Hindu \\ University, Varanasi-221005, Uttar Pradesh \\ ${ }^{2}$ Regional Centre, National Institute of Hydrology, Bhopal-462 016, Madhya Pradesh, India \\ *Corresponding author
}

\section{A B S T R A C T}

\section{Keywords}

Drought severity, Rainfall departure, Relative departure index, Standardized Precipitation Index

Article Info

Accepted: 08 January 2020 Available Online: 10 February 2020
The water resources sector is one of the key sectors facing several challenges in the context of burgeoning population and large scale unsustainable exploitation which will have its consequences for our future generations. More and more areas have to be brought under agriculture to provide the food security to the growing population. The unplanned interventions in the form of deforestation and conversion of forest areas into agricultural land and conversion of agriculture areas to urban centres have its own set of impacts. The adverse effects are visible with reduced water availability and many areas experiencing droughts on a regular basis. Drought scenario for Ajmer district has been analysed using drought indices namely rainfall departure, relative departure index and Standardised precipitation index. Statistical analysis based on coefficient of variance revealed high variability in seasonal rainfall. Most the area is under grip of drought with different severity class in 1985, 1991, 2000, 2002, and 2008. Based on RDI Mangaliawas is at highest priority for drought mitigation practises. Masuda and Mangaliawas are affected with regular occurrence of drought with drought frequency 1 in 2 years. The assessment using SPI revealed the spatio-temporal variability of different station. The present study attempts to assess the meteorological drought response to extreme climate condition. Long-term rainfall data (1985-2008) have been taken for evaluation.

\section{Introduction}

Drought is an abnormal condition that causes due to deficit in rainfall. The reduction in rainfall severely affects the water availability in a region and thus crop productivity is affected. Drought for an extended period causes a considerable hydrologic imbalance and consequently water shortage, crop damage, stream flow reduction and depletion of ground water and soil moisture. It occurs when evaporation and transpiration (the movement of water in the soil through plants into the air) exceeds precipitation for a considerable periods (Framji 1986).

According to Dracup et al., (1980) if one is interested in determining causes and 
characteristics of drought, the attention should be focused on the meteorological (precipitation) droughts. However, if one is interested in determining the effect or impact of drought the attention should be focused on streamflow and agricultural drought.

The most popular perception of drought is, it is a, "meteorological phenomenon", characterized by lack of rainfall compared to the expected amount over a given periods of time. A drought exists when rainfall is below $75 \%$ of the long-term mean (Glantz, 1994), while others might consider it to occur at or below 60 or $50 \%$ of normal.

As per the Indian Meteorological Department (IMD) the droughts is based on the percentage departure of rainfall from the long term mean rainfall.

The study for assessment of meteorological drought characteristics for Ajmer district, Rajasthan has been conducted. The region has hot semi-arid climate. The region mainly depends on monsoon for different agriculture activities and thus poses the risk of crop failure and unprecedented economic losses due to change in rainfall pattern caused due to climate change. It is under this context the study was conducted for assessment of meteorological drought characteristics that help to mitigate and execution of effective drought management planning for future endeavour.

\section{Methodology}

Different methodology was adopted to evaluate the meteorological drought characteristics based on daily rainfall data for 24 years for 9 stations in Ajmer district. The data has been collected from IMD, Pune. Different statistics tool and most famous index namely Standardised Precipitation Index has been used for assessment of drought characteristics.

\section{Location of study area}

Ajmer is situated in the hot semi-arid zone and it is located between $26^{\circ} 27^{\prime} \mathrm{N}$ latitude and $74^{\circ} 37^{\prime}$ E longitude and at an altitude of $475 \mathrm{~m}$ above mean sea level. The Ajmer district received $416.66 \mathrm{~mm}$ rainfall from 1985 to 2016. This region has steppe type of vegetation.

\section{Coefficient of variance (C.V.)}

The inter-annual and inter-decadal variability of rainfall in Chambal Basin over the period of 1985-2008 were examined using the coefficient of variation.

It is defined as follow:

$$
\text { C. } V=\frac{s}{x} * 100
$$

$C . V=$ Coefficient of Variation

$\mathrm{s}=$ Standard deviation

$x=$ Mean of the Time series

\section{Identification of drought prones station}

The drought-prone blocks in the study area have been identified based on probability analysis of annual rainfall (Central Water Commission 1982). An area has been considered to be drought prone if the probability of occurrence of $75 \%$ of mean annual rainfall is less than $80 \%$. The annual rainfall series has been sorted in the descending order, ranks assigned from 1, 2, ...... N, up to the last record and Weibull's distribution fitted to the ranked data. The probability of exceedance is given by Eq. 1 .

$$
P=(m / N+1) * 100
$$

Where, $\mathrm{P}=$ Probability of Exceedence of annual rainfall, $\mathrm{m}=$ rank of particular record, $\mathrm{N}=$ total number of observation 


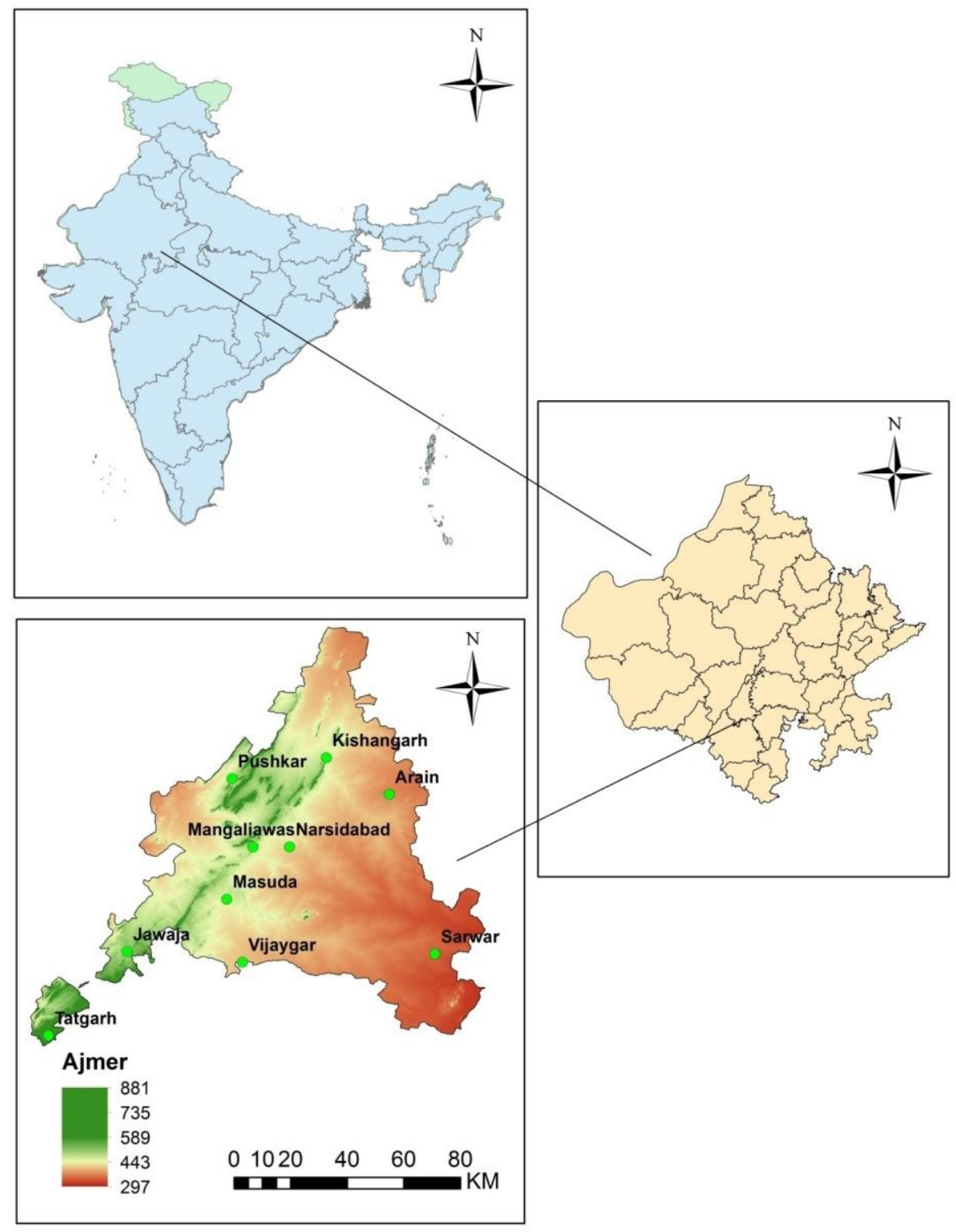

Fig.1 Base map of study area

\section{Identification of drought years}

The drought years can be identified based on the departure analysis of annual and seasonal rainfall time series. Since more than $90 \%$ of the annual rainfall is received during the monsoon season, the seasonal rainfall departure analysis better represents the drought conditions in the study area.

The seasonal rainfall departure (Di) is computed by subtracting the mean seasonal rainfall $(\mathrm{Xm})$ from the seasonal rainfall series (Xi) given by Eq. 2 .

$$
[D i=X i-X m]
$$

The percentage departure (D \%) is subsequently computed as given by Eq. 3 .

$$
\text { [D \% } \left.={ }^{\mathrm{Di} / \mathrm{Xm}} * 100\right]
$$

India Meteorological Department (IMD) considers a season as drought affected, if the total seasonal rainfall is less than $75 \%$ of the 
normal. However, based on the actual field conditions in Chambal River Basin, even a deficit of $20 \%$ in the seasonal rainfall leads to much lesser crop acreage and crop yields. Therefore, four drought classes have been defined for Chambal River Basin based on the seasonal rainfall departures viz., (a) mild drought (b) moderate drought (c) severe drought (d) extreme drought and has following ranges-

Standard Range of Departure values and their classification-

\begin{tabular}{|c|c|c|}
\hline S.No. & Drought Classes & Range (\%) \\
\hline $\mathbf{1 .}$ & Mild Drought & $-20 \%<\mathrm{D}<-25 \%$ \\
\hline $\mathbf{2 .}$ & Moderate Drought & $-25 \%<\mathrm{D}<-35 \%$ \\
\hline $\mathbf{3 .}$ & Severe Drought & $-35 \%<\mathrm{D}<-50 \%$ \\
\hline $\mathbf{4 .}$ & Extreme Drought & $\mathrm{D}>-50 \%$ \\
\hline
\end{tabular}

\section{Relative Departure Index}

Relative departure index (RDI) is a ranking system, used to decide the relative drought proneness of various areas under Chambal basin based on rainfall departure analysis. For this purpose, weights have been assigned to various drought years as follows, (1) mild drought, (2) moderate drought, (3) severe drought and (4) extreme drought. The relative departure index for the rain gauge stations has been decided by dividing the total cumulative weights obtained for the study period during drought years with total number of years under consideration as given in equation below-

$$
R D I=\frac{\sum_{i=1}^{n} W_{\mathrm{i}}}{N}
$$

Where, $\mathrm{N}=$ Total number of year under consideration

$\mathrm{W}_{\mathrm{i}}=$ Weight for the $\mathrm{i}^{\text {th }}$ drought years

\section{Spi - based meteorological drought evaluation}

Standardized Precipitation Index (SPI) was calculated using the following formula and classification scheme as proposed by Mckee et al., (1993). SPI was estimated to observe the spatio-temporal extent and intensity of meteorological drought event. The SPI is a dimensionless index where negative and positive values indicate drought and wet situation respectively. The intensity, magnitude and duration of drought as well as the historical database probability emerging from a specific drought can be determined by a thorough analysis of SPI values.

The normalized series of SPI values represent wetter and drier climates in the same way. The SPI has been applied to quantify monthly precipitation deficit anomalies on single time scale (3 month) for the period during 19852008. Computation of the SPI involves fitting a gamma probability density function to a given frequency distribution of precipitation for a given station.

It represents a statistical z-score or the number of standard deviation (following a gamma probability distribution transformation to a normal distribution); above or below that an event is demarcated with reference to mean (Edward and Mckee, 1997). The gamma distribution is normally defined as:

$$
G(x)=\frac{x^{\alpha-1} \cdot e^{-\frac{x}{x}}}{a^{\alpha} \cdot \sqrt{\alpha}} \quad \text { For }{ }^{x}>0
$$

Where, $\alpha>0$ is a shape parameter, $\beta>0$ is a scale parameter, $x$ is the precipitation amount and $\Gamma(\alpha)$ is the gamma function. 


\section{Results and Discussion}

\section{Statistical Analysis}

The rainfall pattern in the study area is evaluated based on statistical characteristics of annual rainfall. The average annual rainfall for Ajmer district is $416.66 \mathrm{~mm}$ which is slight more than state average which is only $400 \mathrm{~mm}$. In Mangaliawas minimum rainfall occurred in comparison to other station. The variation of the average annual rainfall for the Ajmer district is given in Fig. 2.

The variability in rainfall has significance to the water availability, both surface water and groundwater as lesser runoff will be generated coupled with lesser recharge to the groundwater aquifers.

Also, it has been observed that the variability in the rainfall is very high contributing to regular and frequent occurrence of drought. The variability of the annual rainfall in the study area is given in Table1.

The variability of seasonal rainfall is heights for Mangaliawas followed by Masuda indicating high variability in seasonal rainfall over the region.

\section{Identification of drought year}

The drought years have been identified based on the departure analysis of seasonal rainfall. During the period of analysis spanning 24 years between 1985 and 2008, there have been 6 drought events in Narsidabad, 9 drought events in Masuda, 6 to 7 drought events in Tatgarh, 5 to 6 drought events in Kishangarh, 5 drought events in Sarwar, 6 to 7 drought events in Pushkar, 7 drought events in Vijaygar, 6 drought events in Jawaja, 8 drought events in Arain, 8 to 9 drought events in Mangaliawas. In general, most of the area experienced 6 to 8 drought events which indicate that the drought frequency varies between 1 in 2.5 years to 1 in 5 years for the study area. 1985, 1991, 2000, 2002, and 2008 have been the predominant drought years in which the whole area was under drought.

\section{Identification of drought prone station}

The probability analysis of the seasonal rainfall has been carried out to identify the drought prone station. The drought prone station is given in Table 2. It can be observed that all the stations are drought prone except Sarwar.

\section{Prioritisation of drought prone areas}

The drought severity has been initially evaluated based on the rainfall departure and the droughts classified into four categories viz., mild drought, moderate drought, severe drought and extreme drought based on the severity ranges. The drought severity and frequency of drought is given in Table 3 and Table 4 for the study area. The relative departure index has been used to prioritise the drought prone stations, so that the drought relief and mitigation efforts can be directed initially to these stations which are on the highest priority.

This index helps to identify the higher ranked stations and can also be used to compare the priority amongst all the stations in the study area. The ranking system is based on a weight of 1 for mild drought, 2 for moderate, 3 for severe and 4 for extreme droughts, which are subsequently summed up and normalised. The relative departure index for the stations in Ajmer district, Rajasthan is given in Table 5.

It can be observed that the Mangaliwasis the highest priority station $(\mathrm{RDI}=1.50)$ followed by Masuda (RDI=1.29), Pushkar (RDI=1.08), Tatgarh and Jawaja having (RDI=1.0) Sarwar has the lowest priority. 
Evaluation of Drought Characteristics using SPI

The meteorological and hydrological drought characteristics have been evaluated based on the Standardized Precipitation Index (SPI). The SPI is used to assess the meteorological drought. The 3-month SPI (SPI3) indicates the soil moisture drought. The SPI3 at Magalia is given in Fig. 6.
It can be observed that $1985,1986,1989$, 1991, 1992, 2000, and 2002 have been the drought years with varying degree of severities. The severe soil moisture droughts $(-2.0<\mathrm{SPI} 3<-1.5)$ were observed during 1991, 1992, 1993, and 2002. The number of soil moisture drought events, drought frequency, combined drought severity and the drought frequency can be evaluated from the time series of SPI3.

Table.1 Variability in annual rainfall over Ajmer district, Rajasthan

\begin{tabular}{|l|c|c|c|}
\hline \multicolumn{1}{|c|}{ Station } & Mean & $\begin{array}{c}\text { Standard } \\
\text { deviation }\end{array}$ & Coefficient of Variance \\
\hline Narsidabad & 504.29 & 194.74 & 38.62 \\
\hline Masuda & 464.59 & 261.65 & 56.32 \\
\hline Tatgarh & 451.32 & 179.58 & 39.79 \\
\hline Kishangarh & 420.82 & 189.66 & 45.07 \\
\hline Sarwar & 447.25 & 145.43 & 32.52 \\
\hline Pushkar & 448.13 & 236.23 & 52.72 \\
\hline Vijaygar & 388.45 & 155.69 & 40.08 \\
\hline Jawaja & 386.34 & 179.13 & 46.37 \\
\hline Arain & 346.63 & 146.97 & 42.4 \\
\hline Mangaliawas & 308.79 & 175.82 & 56.94 \\
\hline & & & \\
\hline
\end{tabular}

Table.2 Drought prone stations in Ajmer district of Rajasthan

\begin{tabular}{|l|l|c|c|}
\hline District & Station & Drought prone & No Drought prone \\
\hline \multirow{2}{*}{ Ajmer } & Narsirabad & Yes & \\
\hline \multirow{2}{*}{ Masuda } & Yes & \\
\hline & Tatgarh & Yes & \\
\cline { 2 - 4 } & Kishangarh & Yes & \\
\hline & Sarwar & & Yes \\
\hline & Pushkar & Yes & \\
\hline & Vijaynagar & Yes & \\
\hline \multirow{2}{*}{ Jawaja } & Yes & \\
\hline & Arain & Yes & \\
\hline & Mangaliwas & Yes & \\
\hline
\end{tabular}


Table.3 Drought severity classes for different station in Ajmer district, Rajasthan

\begin{tabular}{|l|c|c|c|c|c|}
\hline Station & Mild & Moderate & Severe & Extreme & Total \\
\hline Narsidabad & 0 & 3 & 1 & 2 & 6 \\
\hline Masuda & 1 & 1 & 4 & 4 & 10 \\
\hline Tatgarh & 1 & 1 & 3 & 3 & 8 \\
\hline Kishangarh & 0 & 4 & 2 & 2 & 8 \\
\hline Sarwar & 2 & 0 & 1 & 2 & 5 \\
\hline Pushkar & 1 & 0 & 3 & 4 & 8 \\
\hline Vijaygar & 0 & 2 & 3 & 2 & 7 \\
\hline Jawaja & 1 & 0 & 1 & 5 & 7 \\
\hline Arain & 0 & 5 & 0 & 3 & 8 \\
\hline Mangaliawas & 1 & 0 & 1 & 8 & 10 \\
\hline
\end{tabular}

Table.4 Drought frequency for different station in Ajmer district, Rajasthan

\begin{tabular}{|l|l|}
\hline Station & $\begin{array}{c}\text { Drought } \\
\text { frequency }\end{array}$ \\
\hline Narsidabad & 1 in 4 years \\
\hline Masuda & 1 in 2 years \\
\hline Tatgarh & 1 in 3 years \\
\hline Kishangarh & 1 in 3 years \\
\hline Sarwar & 1 in 5 years \\
\hline Pushkar & 1 in 3 years \\
\hline Vijaygar & 1 in 3 years \\
\hline Jawaja & 1 in 3 years \\
\hline Arain & 1 in 3 years \\
\hline Mangaliawas & 1 in 2 years \\
\hline
\end{tabular}

Table.5 Shows the prioritization of various stations based on Relative Departure Index

\begin{tabular}{|l|r|}
\hline Station & RDI \\
\hline Narsidabad & 0.71 \\
\hline Masuda & 1.29 \\
\hline Tatgarh & 1.00 \\
\hline Kishangarh & 0.92 \\
\hline Sarwar & 0.54 \\
\hline Pushkar & 1.08 \\
\hline Vijaygar & 0.88 \\
\hline Jawaja & 1.00 \\
\hline Arain & 0.92 \\
\hline Mangaliawas & 1.50 \\
\hline
\end{tabular}


Table.6 Drought characteristics for different station using SPI3

\begin{tabular}{|l|c|c|c|c|c|c|}
\hline Station & Extreme & Severe & Moderate & Duration & $\begin{array}{c}\text { Total } \\
\text { severity }\end{array}$ & Intensity \\
\hline Arain & 4 & 2 & 8 & 13 & -21.09 & -1.62 \\
\hline Jawaja & 3 & 4 & 7 & 14 & -24.5 & -1.75 \\
\hline Kishangarh & 2 & 6 & 14 & 22 & -32.37 & -1.47 \\
\hline Mangaliawas & 3 & 6 & 7 & 16 & -25.1 & -1.57 \\
\hline Masuda & 2 & 5 & 11 & 17 & -25.51 & -1.5 \\
\hline Narsidabad & 5 & 4 & 13 & 22 & -35 & -1.59 \\
\hline Pushkar & 3 & 3 & 10 & 16 & -26.61 & -1.66 \\
\hline Sanwar & 6 & 4 & 12 & 22 & -34.43 & -1.57 \\
\hline Tatgarh & 2 & 3 & 16 & 21 & -29.52 & -1.41 \\
\hline Vijaygar & 4 & 2 & 12 & 18 & -27.8 & -1.54 \\
\hline
\end{tabular}

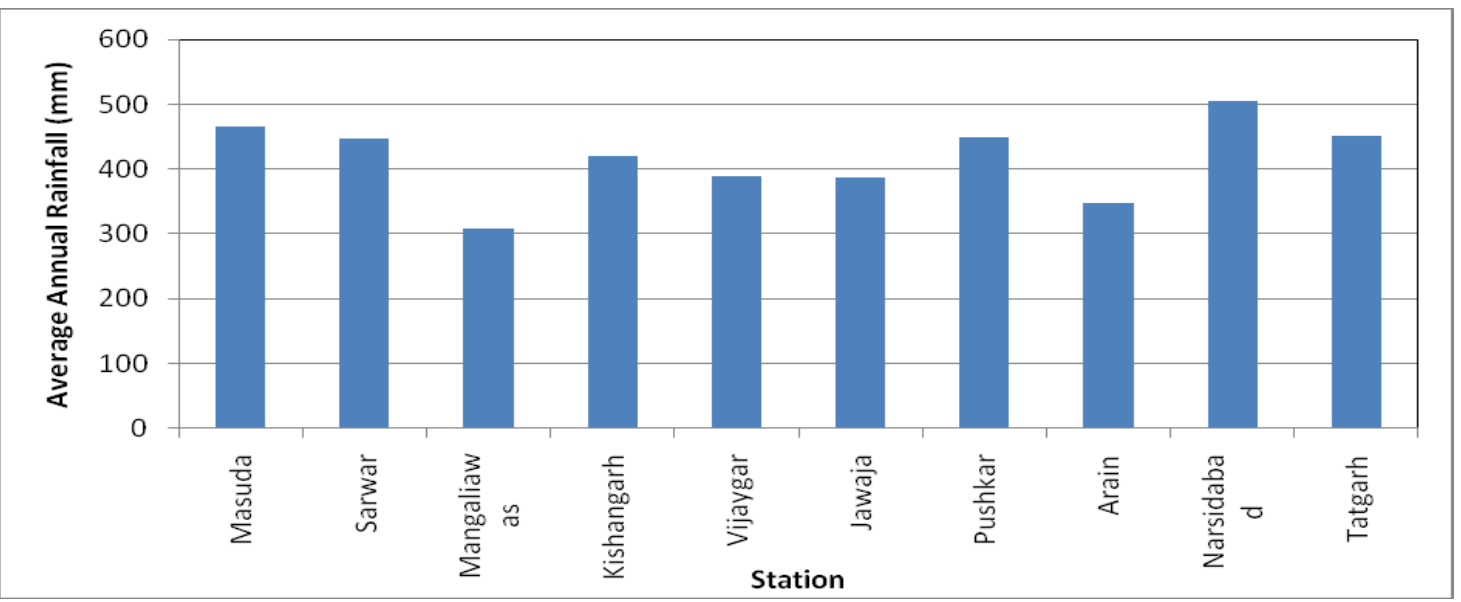

Fig.2 Average annual rainfall for different station in Ajmer district

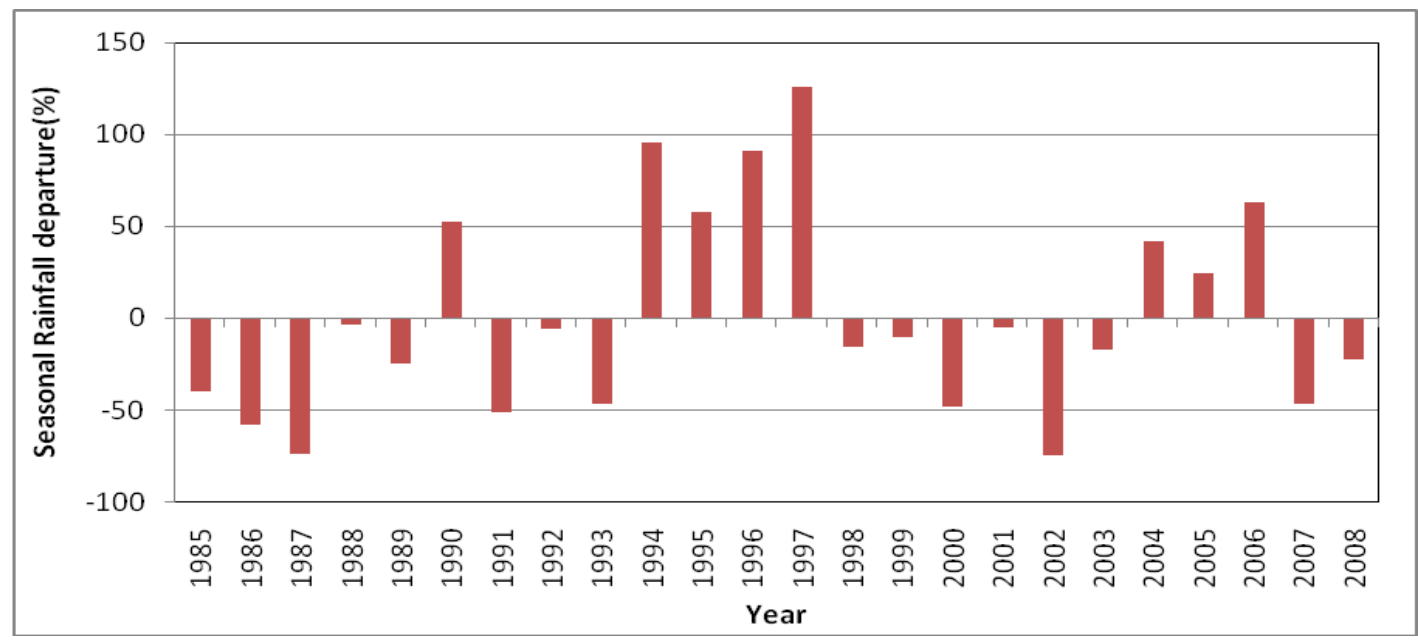

Fig.3 Departure of seasonal rainfall at Masuda station, Ajmer 


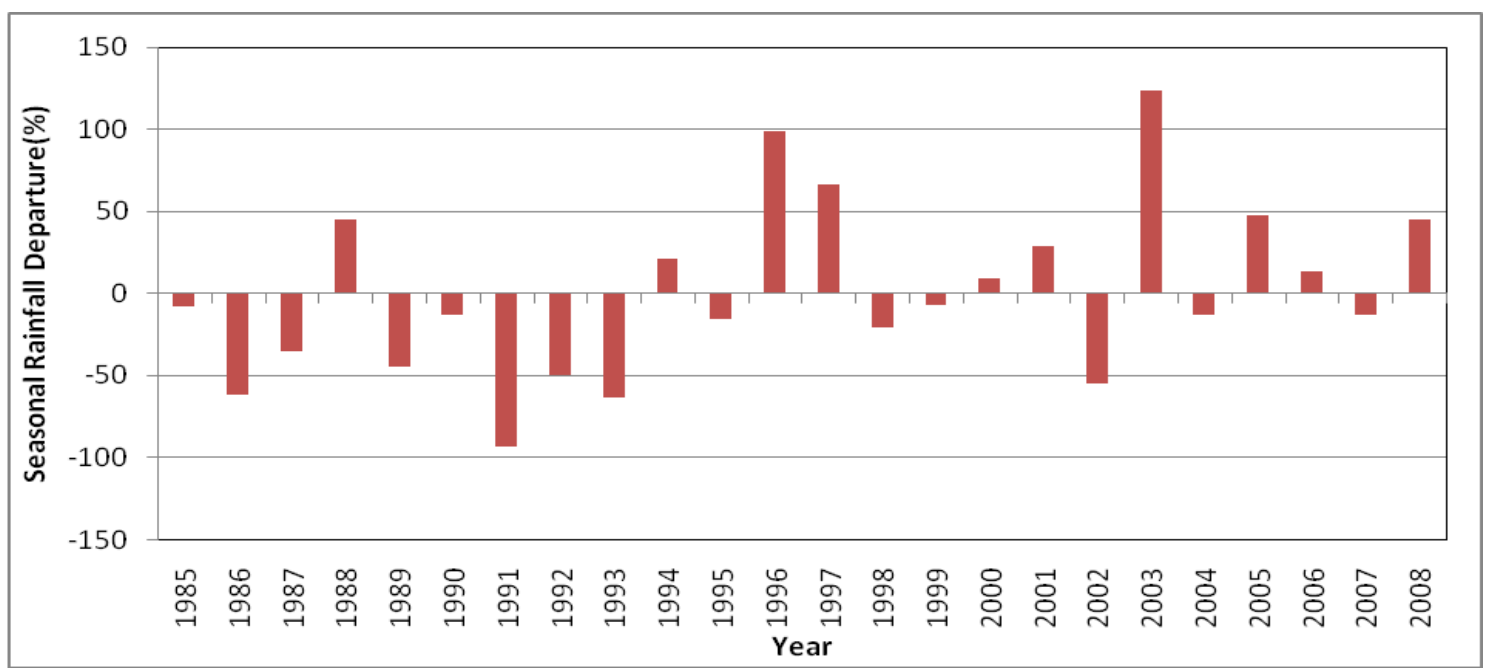

Fig.4 Departure of seasonal rainfall at Pushkar station, Ajmer

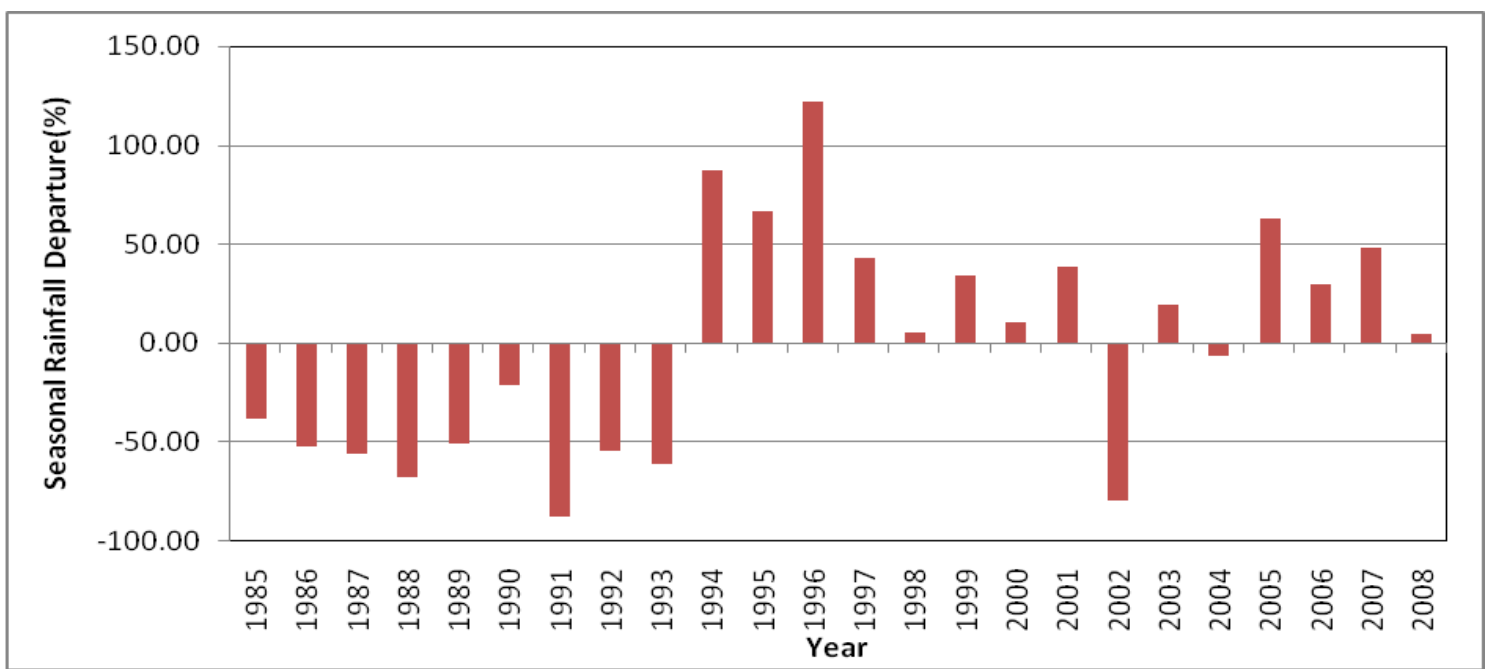

Fig.5 Departure of seasonal rainfall at Mangaliawas station, Ajmer

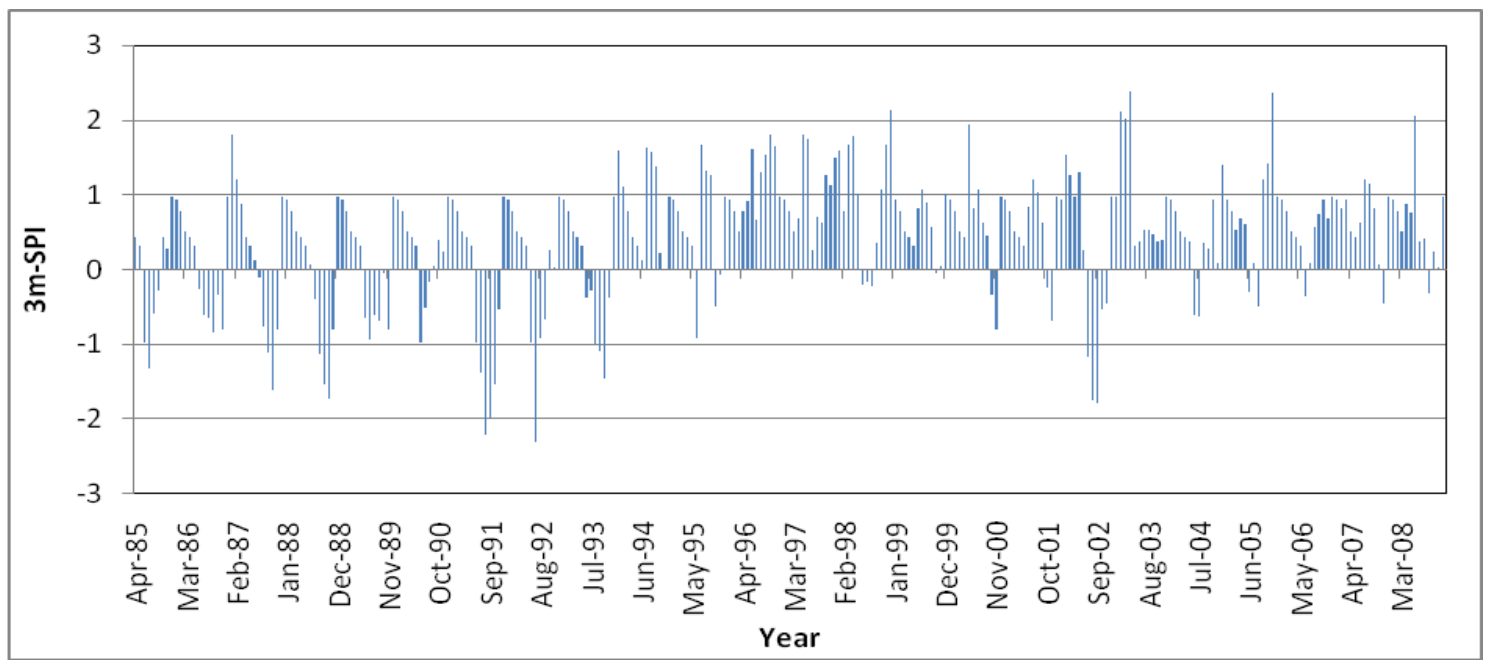


Fig.6 Temporal variation of SPI3 at Mangaliawas, Ajmer

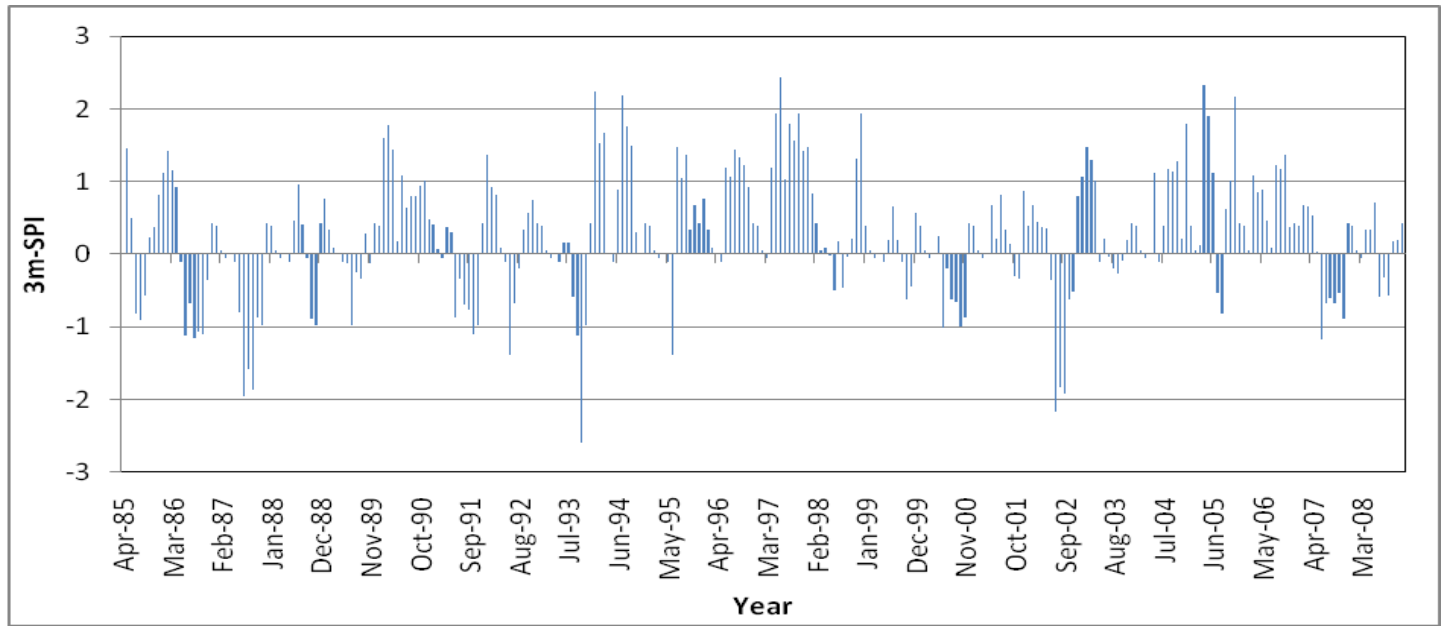

Fig.7 Temporal variation of SPI3 at Masuda, Ajmer

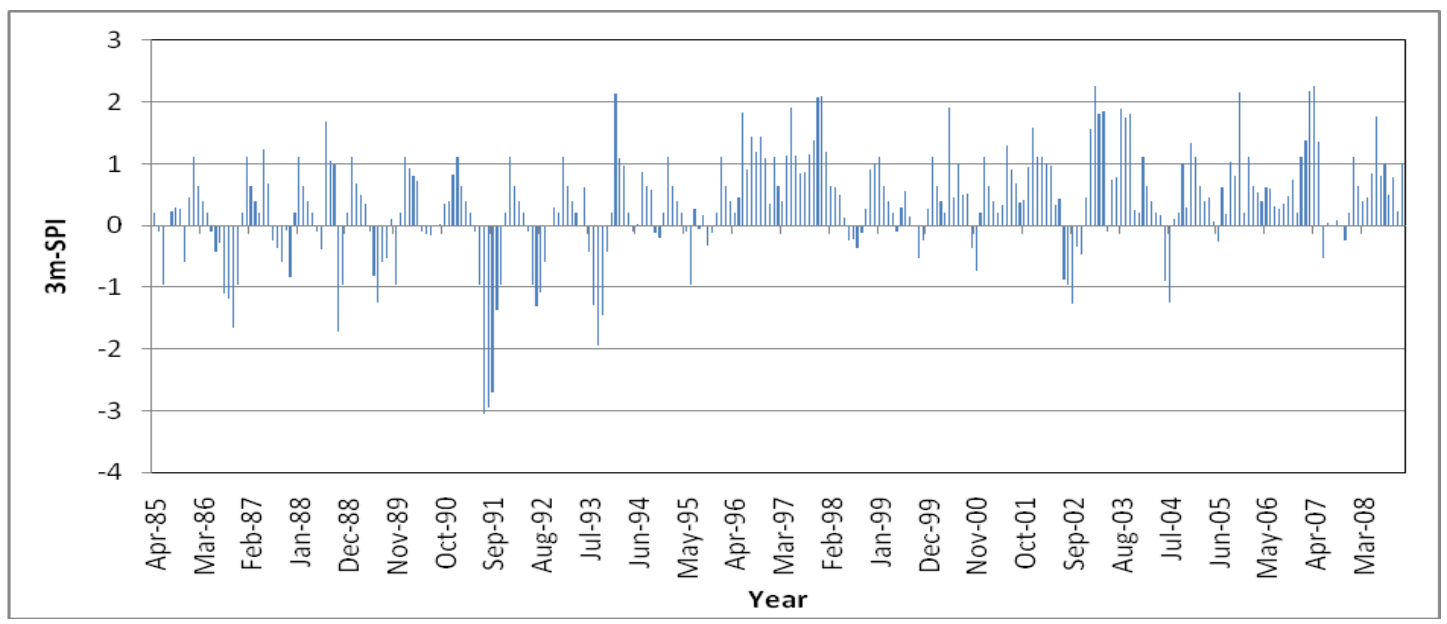

Fig. 8 Temporal variation of SPI3 at Pushkar, Ajmer

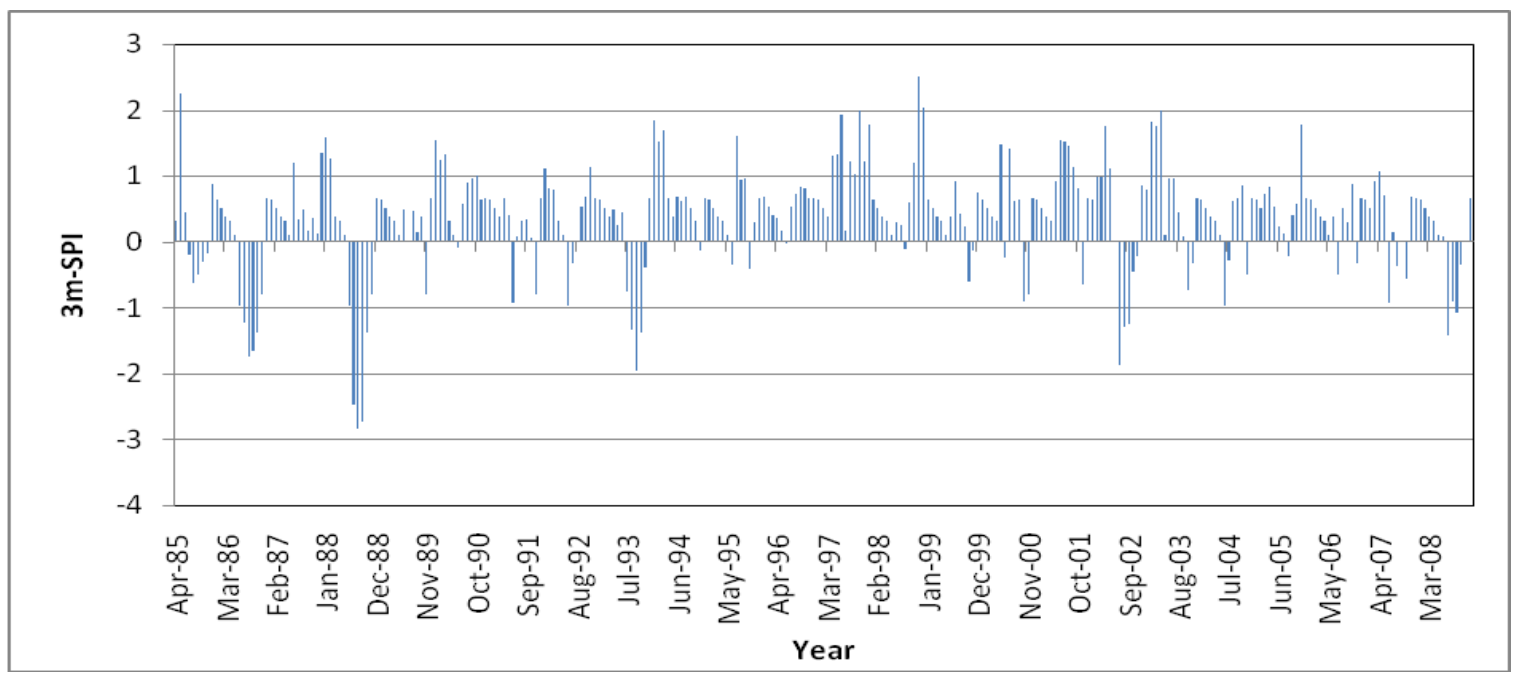

Fig.9 Temporal variation of SPI3 at Jawaja, Ajmer 
SPI is evaluated for various station of Ajmer district. Station namely Masuda, Pushkar and Jawaja are having maximum degree of severity and there temporal variation are depicted in Fig. 7 to 9. Extreme drought events occurred during 1987, 1993, and 2002. The area during these periods is affected due insufficient soil moisture and thus the crop productivity is severely affected.

It is observed that maximum extreme events occurred in Sanwar followed by Narsidabad. In most of the area the occurrence of extreme drought events on an average is 3. Maximum number of time severe drought events occurred at Kishangarh and Mangaliawas. Moderate drought events are frequents in the region. Based on SPI evaluation maximum drought intensity occurred at Jawaja followed by Pushkar.

A systematic and comprehensive meteorological drought analysis has been carried out for Ajmer district, Rajasthan and the spatio-temporal characteristics of meteorological drought have been evaluated. The meteorology based Standardized Precipitation Index (SPI) has successfully revealed the drought scenario from 1985 to 2008. The SPI with geospatial techniques proves to be a robust technique for identifying the spatio-temporal drought stress over the region. Based on prioritization using RDI, station is identified for mitigation. Departure analysis helps in drought characterisation based on which frequency of occurrence of drought is evaluated based on which planning and execution of proper implementing strategies are adopted to cope under such drought condition.

\section{References}

Dracup, J. A., Lee, K. S. and Paulson, E. G., 1980. On the definition of droughts.
Water Resources Research, 16(2), 297302.

Framji, K. K., 1986. Drought alleviation and management. ICID bulletinInternational Commission on Irrigation and Drainage.

Glantz, M. H., 1994. Drought, desertification and food production. Drought follows the plow, M. H. Glantz, (eds.), Cambridge University Press, Cambridge, England, 929.

Kar, S. K., Thomas, T. and Singh, R. M., 2016. Identification of drought prone areas andtrend analysis of rainfall phenomenon in Dhasan basin. Indian Journal Dryland Agriculture Research \& Development 31(2), 09-14.

Kundu, A., Denis, D. M. and Patel, N. R., 2015. Evaluation of the meteorological drought over the Bundelkhand region using geo-spatial techniques. Climate Change, 1(4), 418-424.

Mckee, T. B., Doesken, N. J. and Kleist, J. 1993. The relationship of drought frequency and duration to time scales. AMS 8th Conference on Applied Climatology, (January), 179-184.

Sandeep, P., 2018. Analysis of Meterological Drought for Ajmer and Bikaner District of Rajasthan. International Journal of Agricultural Science and Research. 8. 27-32.

Thomas, T., Jaiswal, R. K., Nayak, P. C. and Ghosh, N. C. 2015. Comprehensive evaluation of the changing drought characteristics in Bundelkhand region of Central India. Meteorology and Atmospheric Physics, 127(2), 163-182.

Thomas, T., Nayak, P. C. And Ghosh, N. C. 2015. Spatiotemporal Analysis of Drought Characteristics in the Bundelkhand Region of Central India using the Standardized Precipitation Index. Journal of Hydrologic Engineering, 20(11). 


\section{How to cite this article:}

Gaurav Sharma, Chandra Kishor Kumar and Ankit Kumar. 2020. Assessment of Meteorological Drought characteristics using Standardized precipitation Index for Ajmer district, Rajasthan, India. Int.J.Curr.Microbiol.App.Sci. 9(02): 1343-1354.

doi: https://doi.org/10.20546/ijcmas.2020.902.157 